\title{
ПРАКТИКА ОТБОРА ПРОБ СНЕЖНОГО ПОКРОВА ДЛЯ ХИМИЧЕСКОГО АНАЛИЗА
}

\author{
Янченко Наталья Иванова, \\ fduecn@bk.ru \\ Иркутский национальный исследовательский технический университет, \\ Россия, 664074, г. Иркутск, ул. Лермонтова, 83.
}

\begin{abstract}
Актуальность исследования обусловлена необходимостью изучения химического состава снежного покрова для оценки качества воздуха и сопредельных сред в условиях изменения климата, что подтверждается устойчивым ростом научных публикаций по данной теме. В то же время практически отсутствуют современнье публикации по методике отбора проб снежного покрова для аналитических целей.

Цель: исследовать практики отбора проб снежного покрова для аналитических определений на основе обзора научнотехнической информации. Современные усовершенствованные методы отбора снежного покрова необходимы для получения наиболее достоверных данных о химическом составе снежного покрова, являются основой для оценки динамики качества воздуха и природоохранных мер, а также будут способствовать научному пониманию химических процессов, связанных со снегом в условиях изменения климата.

объекты: нормативная и научно-техническая информация по методологии отбора проб снежного покрова для химического анализа; способы подготовки снежного покрова перед отбором проб; приборы, оборудование, средства, приспособления для отбора проб снежного покрова с целью определения плотности (физический показатель) и химического состава снежного покрова.

Методы: обзор научно-технической информации и систематизация сведений.

Результаты. Современная исследовательская практика отбора проб снежного покрова для химического анализа имеет свои особенности, отличные от рекомендуемых практик, разработанных в основном в 1990-х г2. Это обусловлено растущим количеством определяемых химических компонентов снежного покрова и требованиями достоверности отбора проб. Применяемые в настоящее время авторские практики отбора проб снежного покрова для химического состава снежного покрова имеют как общие этапы, так и отличия в зависимости от географической точки отбора и определяемого химического компонента. В настоящее время для отбора проб для исследования химического состава снежного покрова применяется большое разнообразие вспомогательных средств, устройств, приспособлений, не входящих в реестр измерительных средств для химического анализа снежного покрова, что вызывает необходимость совершенствования методик отбора проб снежного покрова и развития прикладного приборостроения в области химического снеговедения. Целесообразно разработать согласованные (типовые) методики отбора проб снежного покрова для химического анализа с учетом определенных географрических регионов.
\end{abstract}

Ключевые слова:

Снежный покров, отбор проб, пробоотборник, химический компонент, методика.

\section{Введение}

Снег обеспечивает одну шестую часть населения планеты талой водой и практически все население планеты получает пользу от охлаждения Земли при сохранении теплового баланса, так как снег отражает солнечную энергию [1], также снег поддерживает процветающую в настоящее время индустрию зимнего отдыха на природе. M.M. Sturm пишет [1], что на сегодняшний день полная финансовая оценка значимости снега в нашей жизни (Канада) не проводилась, но расчеты здесь и в других местах показывают, что она составляет порядка триллионов долларов. В противовес этому значению текущие затраты на научные исследования тривиальны [1]. Исследования снега будут иметь все более важное значение для управления пресными водными ресурсами, смягчения последствий изменения климата, управления экономикой снежных районов [2, 3], для адаптации к новым климатическим условиям и оценки рисков (таких как лавины и наводнения), для учета удовлетворения новых потребностей, связанных со сведениями о снеге [4]. Появятся новые потребности в исследовании параметров снега, например, при современном освоении Арктики и Антарктики. Недостаток знаний о снеге считается самым большим пробелом в современных представлениях о глобальном водном балансе [5].
Важной составляющей исследования снежного покрова является изучение его химического состава для оценки качества воздуха и поверхностных вод, состояния сопредельных сред или для палеоклиматических исследований. В настоящее время исследования химического состава снежного покрова (ХССП) также необходимы в связи с тем, что характер распределения загрязняющих веществ существенно изменится с изменением климата, в частности с ростом температуры и изменением количества осадков в отдельных регионах [6].

Но наблюдения за химическим составом снежного покрова на месте немногочисленны по сравнению с измерениями физических свойств снега, которые могут быть дистанционными или автоматизированными [1]. Обзор информации позволяет сделать вывод, что зарубежными учеными более активно исследуется наличие черного углерода, компонентов биоты, химических веществ во льдах и снегах Арктики, Антарктики, горных массивах, городских территориях. В РФ большинство публикаций посвящены химическому составу снежного покрова в населенных пунктах или в ближних районах атмосферного техногенного влияния, что связано прежде всего с доступностью объекта, так как отбор снега - это всегда финан- 
сирование экспедиционных исследований разного масштаба.

Обзор данных об исследовании химического состава снежного покрова в РФ свидетельствует, что наблюдается устойчивый рост публикаций. Если провести запрос в e-laibray на слова «химический состав снежного покрова» (аннотации, статьи в журналах, ключевые слова, полный текст статей), то будет найдено 288 публикаций из 30621756 в 2010 г., $353-$ 2013 г., 424 - 2016 г., 378 - 2017 г., 407 публикаций из 30621756 в 2018 г. (Дата обращения 15.09.2019). На территории России актуальность исследования СП не вызывает сомнений. По данным [7. С. 9] продолжительность устойчивого снежного покрова (Т дни) с указанием коэффициента вариации (с $\left.\mathrm{c}_{\mathrm{T}} \%\right)$ составляет для: «Мурманское УГКС 193 дней $\left(3 \mathrm{c}_{\mathrm{T}}, \%\right)$, СевероЗападное УГКС 150 дней $\left(12 \mathrm{c}_{\mathrm{T}}, \%\right)$, ВерхнеВолжское УГКС 156 дней $\left(5 \mathrm{c}_{\mathrm{T}}, \%\right)$, Уральское УГКС 164 дня (5 c, \%), Западно-Сибирское УГКС 175 дней (5 c, \%), Иркутское УГКС 196 дней $\left(5 \mathrm{c}_{\mathrm{T}}, \%\right)$ \%. В то же время публикаций, посвященных методологии и практике отбора проб снежного покрова для химического анализа макро и микро-количеств веществ и элементов, практически нет, несмотря на доступность многих аналитических исследований.

Известно, что отбор проб - это одна из важных стадий проведения анализа. Достоверность исследования химического состава снежного покрова зависит не только от современного оборудования, квалифицированных специалистов, но и от соблюдения методологии отбора проб. Результаты химического анализа, полученные на основе недостоверного, некорректного пробоотбора, могут привести к неверной интерпретации результатов анализа и выводам.

В.Н. Василенко пишет [7], что систематические наблюдения за ХССП были организованы в начале 1980-х гг. на базе существовавшей в то время снегомерной сети. Исследователи В.А. Ветров, В.В. Кузовкин, Д.А. Манзон [8] указывают, что создание системы мониторинга ХССП позволило впервые в мировой практике получить детальную картину загрязнения снежного покрова на обширных территориях и её изменений во времени. «Сеть мониторинга ХССП на территории РФ в 2016 г. включала 528 пунктов наблюдений (ПН), из них на Европейской территории РФ - 268, на азиатской территории РФ - 260. В настоящее время в пробах снежного покрова, отбираемых ежегодно перед активным снеготаянием, определяются кислотность (pH) и концентрации макроионов - $\mathrm{SO}_{4}{ }^{2-}, \mathrm{NO}^{3-}, \mathrm{Cl}^{-}, \mathrm{HCO}^{3-}, \mathrm{NH}^{4+}, \mathrm{Na}^{+}, \mathrm{K}^{+}, \mathrm{Ca}^{2+}$, $\mathrm{Mg}^{2+}$. По результатам наблюдений строятся картысхемы принятых в современный период показателей «р» мониторинга ХССП: $\mathrm{pH}$ (кислотность) снежного покрова и интенсивность атмосферных выпадений серы IS и азота IN (кг/км ${ }^{2} \cdot$ мес) в каждом ПН наблюдений в зимний период» [8. С. 93].

В настоящее время исследователи различных организаций определяют в основном следующие химические компоненты снежного покрова: водорастворимые и нерастворимые соединения (черный углерод, органический углерод, атмосферные аэрозоли); мак- ро- и микропримеси веществ; макро- и микроэлементный состав; водорастворимые органические соединения; некоторые полициклические ароматические углеводороды; изотопы; минерализацию; рН и другие.

\section{Краткие хронологические сведения о нормативной и научно-технической литературе в РФ, содержание методологии отбора проб снежного покрова для химического анализа (с 1970-х гг.)}

В 1971 г. была издана книга И.Д. Копанева «Методы изучения снежного покрова» [9]. В 1982 г. в Институте минералогии, геохимии и кристаллохимии редких элементов опубликованы методические указания по геохимической оценке источников загрязнения окружающей среды [10] и загрязнения химическими элементами территорий городов [11] с указанием роли снежного покрова.

В 1985 г. в Госкомгидромете утверждены «Временные методические указания для производства отбора и обработки проб снежного покрова в городах и их окрестностях на комплекс загрязняющих веществ». Предлагается организация представительной сети отбора проб в городе [12].

В 1985 г. издана книга В.Н. Василенко, И.М. Назаров, Ш.Д. Фридмана «Мониторинг загрязнения снежного покрова» [7]. Как указано в работе, «картину пространственного распределения загрязняющих веществ в снежном покрове удобно характеризовать тремя картами: распределения концентрации загрязняющих веществ (мг/л); количества загрязняющих веществ, выпавших за время от образования снежного покрова до момента накопления максимума влагозапаса в снеге - поверхностной плотности (т/км²); интенсивности выпадения загрязняющих веществ (кг/км ${ }^{2}$ ссут)» [7. С. 59]. Поэтому для интерпретации результатов важно знать не только концентрацию загрязняющего вещества, но и учитывать количество снеговой воды (проба снежного покрова), влагозапас, дату отбора пробы, дату установления снежного покрова и площадь отбора пробы снежного покрова.

В 1989 г. Госуомгидрометом и Главным Государственным санитарным врячом СССР утверждено «Руководство по контролю загрязнения атмосферы. РД 52.04.186-89», которое содержит раздел 5. Наблюдения за загрязнением снежного покрова. В РД 52.04.186-89 указано, что для отбора проб снега используют стандартный снегомер-плотномер, при пробоотборе каждый керн вырезается на полную глубину снегового покрова, что перед ссыпанием снега в полиэтиленовое ведро или пакет тщательно очищается нижний конец снегомера и снежного керна от грунта и растительных включений [13].

В 1990 г. утверждены «Методические рекомендации по оценке степени загрязнения атмосферного воздуха населенных пунктов металлами по их содержанию в снежном покрове и почве», которые предназначены для работников организаций, занимающихся охраной окружающей среды в городах. Рекомендации подготовлены в Институте минералогии, геохимии и кристаллохимии редких элементов Мингео СССР и 
АН СССР (ИМГРЭ) [14]. В п. 2.5 указано «Пробы снежного покрова отбираются на всю мощность из шурфов или снегоотборниками, обязательно фиксируется площадь шурфа и время снегостава. Размеры шурфа замеряются по длине и ширине для расчета площади, на которую проектируются выпадения из атмосферы» [14. С. 4].

В 1990 г. издана коллективная монография «Геохимия окружающей среды» Ю.Е. Саета, Б.А. Ревича, Е.П. Янина и других авторов [15]. В 1994 г. утверждены РД 52.44.2-94 «Методические указания. Охрана природы. Комплексное обследование загрязнения природных сред промышленных районов с интенсивной антропогенной нагрузкой» [16].

В 2010 г. утверждены приказом Министерства экологии и природных ресурсов Республики Татарстан «Методические рекомендации. Оценка аэротехногенного загрязнения природных сред химическими элементами по результатам мониторинга снежного покрова» [17].

В 2016 г. опубликованы рекомендации 52.18.851-2016. «Основные средства измерений гидрометеорологического назначения, применяемые на государственной наблюдательной сети» [18], в которых указано применение снегомера весового ВC-43 (номер в Госреестре средств измерений 22529-02) и снегомера составного М-78 для измерения высоты, плотности и водного эквивалента снежного покрова.

\section{Практика измерения плотности снежного покрова}

Эти практики измерения рассмотрены в связи с тем, что с учетом целей исследования возможно их применение для отбора проб для ХССП. Известный исследователь снежного покрова И.Д. Копанев указывает, что главная физическая (ныне геофизическая) обсерватория занималась вопросами организации снегомерной сети, разработки методики наблюдений и обработки материалов. Здесь в 1893 г. была составлена первая инструкция для наблюдения над снежным покровом и метелями, а в 1903 г. была подготовлена инструкция для наблюдений над плотностью снежного покрова [9].

Известно устройство для отбора проб снега, по которому определяют физические характеристики снегового покрова (плотность), - снегомер ВС-43 [13, 18, 19], состоящее из металлического цилиндра и весов, механически соединенных подвесом. По данным [18] снегомер весовой ВC-43 имеет номер 22529-02 в Госреестре средств измерений и предназначен для измерений высоты, плотности, водного эквивалента снежного покрова. В.В. Козин, Э.А. Кузнецова [20] пишут, что «на каждом участке измерялась (в трех точках) плотность снега с помощью весового снегомера...». Далее авторы В.В. Козин, Э.А. Кузнецова [20] делают ссылку на Рекомендации 1989 и 1990 гг. [9, 13].

Усовершенствованный снегомер весовой $\mathrm{BC}-43 \mathrm{M}$ зарегистрирован в реестре государственных средств измерений [21]. Снегомер весовой ВС-43М применяют при проведении снегомерных съёмок на гидрометеорологических станциях и постах и в различных отраслях народного хозяйства. Известно, что снего- мер предназначен для измерения высоты и массы вырезаемого столбика пробы снега. Плотность снега рассчитывается из полученного веса и объема пробы. Приемная площадь цилиндра равна $50 \pm 0,4 \mathrm{~cm}^{2}$. Товар сертифицирован. Номер в государственном реестре 57925-14.

Авторский коллектив Г.Г. Гулякина предлагает «Способ отбора проб снега и устройство для его осуществления» [22] и «Устройство для отбора проб снега» [23]. Изобретения относятся к метеорологическим, гидрологическим, гидрохимическим и экологическим исследованиям и могут быть использованы для изучения плотности, запасов и химического состава снега и исследования снеговых свалок [23]. Известен пробоотборник снегомерный [24] А.П. Сергеева, А.Г. Буевича, Д.Б. Берга. При описании своего изобретения авторы указывают, что «основным недостатком при использовании снегомера ВC-43 для отбора проб снега является недостаточная точность отбора пробы. Причинами этого являются конструкция цилиндра и его материал, в частности: в результате нагрева металлического цилиндра солнцем или при транспортировке в салоне автомобиля его температура часто оказывается выше $0{ }^{\circ} \mathrm{C}$, что при относительно высоких значениях его теплопроводности и теплоемкости ... приводит к налипанию снега на поверхность цилиндра (изнутри и снаружи), особенно в температуре воздуха около $0{ }^{\circ} \mathrm{C}$, а именно такие условия наблюдаются при снегомерной съемке максимального влагозапаса и загрязнения снежного покрова....налипание снега на поверхность цилиндра снаружи искажает вес пробы, а налипание внутри - и вес, и объем пробы; цилиндр с малым внутренним диаметром (около 80 мм)...при отборе пробы сминает снег, а не прорезает его, что приводит к искажению веса и объема пробы, а также завышению плотности снега..» [24. С. 9, 10]. Авторы предлагают снегомер с пластиковым цилиндром увеличенного диаметра и возможностью уплотнения пробы непосредственно в цилиндре, что повышает точность определения физических и химических характеристик снегового покрова и сокращает время отбора каждой пробы.

В работе исследователя И.Д. Копанева [10] указано, что для измерения высоты и плотности снежного покрова используется составная дюралюминиевая трубка, состоящая из нескольких секций. Секция имеет длину 76 см, внутренний диаметр 3,77 см. Нижняя часть трубки имеет пилообразную резьбу. Труба может состоять из отдельных секций, общая длина -608 см. Чтобы снизить потери снега из трубки, при извлечении ее из снега рекомендуется с помощью резьбы захватывать некоторое количество почвы, которая служит пробкой. «Рекомендации 52.18.851-2016» [18] также указывают на «Снегомер составной М-78». В описании [22, 23] указано, что устройство предназначено для отбора проб снега (снегомер составной М-78) и содержит систему металлических труб (до четырех с суммарной длиной до 3,5 м), соединенных при помощи байонетного затвора, а также содержит рейку с измерительной шкалой, 
указателем, уравновешивающим грузом, серьгой и призмой с подвесом, механической связью» [22, 23].

Известно руководство по отбору проб снежного покрова департамента сельского хозяйства США (United States Department of Agriculture, Natural Resources Conservation Service, National Water and Climate) [25]. Целью данного руководства является содействие эффективной и точной снежной съемке и установление единых процедур отбора проб. Это учебное и справочное руководство предназначено для геодезистов, которые используют оборудование для отбора проб для измерения накопления снега. В нем объясняются процедуры отбора проб и регистрации, необходимые для точных прогнозов водоснабжения страны. Показано применение составного пробоотбрника.

D. Dixon, S. Boon в своей работе [26] рассматривают три конструкции пробоотборников, предназначенных для измерения водного эквивалента, с целью оценки точности измерений. Три пробоотборника сравнивали (А: SnowHydro, B: MSC, C: Standard Federal) в условиях мелкого, сильно расслоенного снега. Полученные результаты сравнивали уже с результатами, полученными методикой отбора проб методом шурфа. Исследователи N.J. Kinar, J.W. Pomeroy [27] выполнили обзор методов измерения и соответствующих устройств, используемых для определения физических свойств сезонного снежного покрова, с расстояний, близких к поверхности земли. Указано, что снежная труба, которая используется большинством исследователей снежного покрова, изготовлена из металла или прозрачного пластика с зубчатым режущим концом. Прозрачная пластиковая труба позволяет исследователю визуально наблюдать образец снега после того, как он был извлечен, хотя металлические пробоотборники для снега часто имеют прорези, чтобы можно было увидеть образец снега. Образец извлекается путем проталкивания трубки через снежный покров пока зубчатый режущий конец не достигнет поверхности земли. Ручки на верхней части трубки позволяют поворачивать пробоотборник так, чтобы зубчатый режущий конец извлекал пробку из почвы. Для сравнения, некоторые снежные трубки, использовавшиеся в прошлом, были просто контейнерами, которые применялись для отбора проб снега [27]. Использование снежных трубок было впервые популяризировано J.E. Church в книге «Snow surveying: its principles and possibilities» [28]. На сайте Western Snow Conference [29] указано о применении различных пробоотборников, которые имеют разную площадь отбора, в зависимости от типа и глубины снега.

R. Pirazzini [30] пишет об обзоре N.J. Kinar [27], что их историческая перспектива иллюстрирует развитие и современное состояние отрасли с упором на практики, применяемые в Северной Америке и Канаде, которые, однако, не полностью соответствуют нынешним практикам, которые используют Европейские институты. Она также пишет о результатах анкетирования по вопросу исследования снежного покрова. Измерения снега на месте, проводимые европей- скими институтами для оперативных исследовательских и энергетических бизнес-приложений, были обследованы в рамках действия Европейского сотрудничества в области науки и техники (COST) ES1404, названного «Европейская сеть для согласованного мониторинга снега для преимущества сценариев изменения климата, гидрологии и численного прогноза погоды». Авторы представили результаты этого опроса, на который ответили 125 участников из 99 операционных и исследовательских учреждений, принадлежащих к 38 европейским странам [30]. 93 \% респондентов измеряют макрофизические параметры снега, такие как наличие снега, глубина снега (HS height snow), эквивалент снежной воды (SWE - snow water equivalent) и плотность снега. Параметры, характеризующие микроструктурные свойства снега (такие как размер и форма снежного зерна и удельная площадь поверхности), электромагнитные свойства снега (такие как альбедо, яркостная температура и обратное рассеяние) и состав снега (такие как примеси и изотопы) измеряются 41, 26 и $13 \%$ респондентов, соответственно, в основном для исследовательских целей.

\section{Средства, устройства, приспособления, способы и приемы отбора проб снежного покрова для химического анализа}

Выполнение среза снежного покрова и отбор проб c помощью пластин. Известен снегоотборник М.П. Тентюкова. В описании указано, что «изобретение относится к области защиты окружающей среды и предназначено для послойного опробования снежной толщи с регулируемым шагом отбора проб при выявлении аэротехногенного загрязнения поверхности снега в результате осаждения сульфатов из приземного слоя воздуха при образовании поверхностного инея» [31. С. 62].

Отбор проб пластиковым цилиндрическим пробоотборником. Авторы [32] указывают, «что снегоотборник представлял собой пластиковую трубу диаметром 14,5 см. Отбор снегового керна проводился из ненарушенной стенки траншеи, выкапываемой до поверхности почвы. Керн отбирался последовательно сверху вниз частями. Высота отдельных частей керна могла варьировать от 15 до 50 см и более в зависимости от плотности снегового покрова» [32. С. 62, 63].

Н.С. Касимов, Н.Е. Кошелева и другие указывают, что «снегомерная геохимическая съемка проведена в начале марта 2010 г. при максимальной высоте снежного покрова. Смешанные пробы из 10 отдельных проб отбирали с шагом 500-700 м пластиковой трубой диаметром 5 см в 51 точке на территории округа и в 5 фоновых точках в 50 км на запад от Москвы в районе г. Звенигород» [33. С. 15]. Также применение подобного устройства с указанием на химическую инертность пробоотборника описано в работе Т.И. Прожориной, Е.В. Беспаловой, С.А. Куролап, П.М. Виноградова [34]. Авторы пишут, что «репрезентативные пробы "лежалого" снега отбирались по всей толще снежного покрова, за исключением нижних 2-3 см (во избежание загрязнения частицами 
почвы). Отбор проб проводился пластиковой трубкой площадью сечения 78,5 см² и длиной 30 см. В месте отбора пробы трубу врезали на всю толщину снежного покрова до поверхности земли. После чего трубку из снега вынимали, поддерживая снизу пластмассовой лопаткой. Нижнюю часть трубки тщательно очищали от частиц грунта» [34. С. 29]. Исследователи Н.В. Салтан, Е.П. Шлапак, В.К. Жиров, О.Б. Гонтарь, Е.А. Святковская также указывают, что «смешанные пробы снега отбирались с помощью пластиковой трубы длиной 1,15 м и диаметром 10 см. Одна проба могла содержать от 4 до 15 кернов в зависимости от плотности и мощности снежного покрова. Снег отбирался на всю глубину за исключением нижнего слоя в 3-5 см, чтобы избежать загрязнения проб снега с подстилающей растительностью и почвой» [35. С. 329]. Рекомендации [17. С. 6] указывают, что «снегоотборник представляет собой пластиковую трубу (длина в пределах 800-1000 мм) с определенным диаметром (в пределах 80-100 мм), снабженную дополнительно для предотвращения потерь снега в процессе отбора уплотняющим снежную массу поршнем. Нижний конец снегоотборника фальцуется для облегчения вхождения его в снежный покров, а по внешней поверхности наносится градуировка в см для определения высоты снежного покрова». В рекомендации [17] применяют пробоотборник А.Р. Валетдинова [36].

Отбор снежного покрова с использованием шурфа u кернового бурения. С. Кутузов, М. Шахгеданова, К. Вайт, М. Вудейдж, В. Михаленко, И. Лаврентьев, Г. Носенко указывают, что при выполнении совместного проекта Института географии РАН (г. Москва) и Университета г. Рэдинг по определению влияния поверхностного загрязнения на таяние льда на Кавказе была разработана специальная методика анализа горизонтов загрязнения в снежных шурфах [37]. Авторы пишут, что было проведено неглубокое керновое бурение на западном плато Эльбруса и отобраны образцы снега и фирна [37]. Исследователи применили перчатки для исключения вторичного загрязнения пробы. В работе [38] указано, что в течение зимнего сезона в 2014 г. проводился отбор свежевыпавшего снега и интегральных проб из снежных шурфов в окрестностях р. Баренцбург и пос. Лонгйир. Фрагмент методики: «Перед тем как выкопать снежный шурф, производилось тщательное исследование местности, для того, чтобы исключить действие посторонних факторов, таких как: ветряной надув у подножий склона и переотложение снега в открытых частях горных долин... После изготовления снежного шурфа, его строго вертикальная стенка зачищалась с помощью пластмассовой лопатки или совка, предотвращающих попадание загрязнений от железной лопаты. Далее в шурфе выделялись горизонты, которые описывались. Для выделения равномерной пробы из шурфа использовался бур (аналогичный используется для бурения льда). Выделенный объем снега из шурфа отбирался в пластмассовые герметичные контейнеры» [38. С. 107].

Отбор снежного покрова с использованием шурфа и пробы в виде прямоугольного параллелепипеда. Как указано в работе В.Н. Макарова, при отборе проб в Якутии «в стенке шурфа вырезался блок в виде прямоугольного параллелепипеда на всю высоту снега от дневной поверхности до земли или льда. Ширина блока фиксировалась, объем снега составлял величину около 3 дм $^{3} .$. На территории Якутии снег отбирался как путем точечного опробования - для региональной характеристики химического состава снежного покрова, так и площадным методом на локальных участках» [39. С. 22].

Отбор снежного покрова рамкой. Авторами [40] определен химический состав снежного покрова в заповедниках Прибайкалья. Указано, что из снега на всю его высоту вырезалась колонка, измерялась ее площадь и высота, пластиковой лопаткой снег переносился в полиэтиленовые мешки для транспортировки в лабораторию. На фотографии с названием «Отбор проб снежного покрова на Байкальской природной территории. По результатам анализов производится расчет накопления загрязняющих веществ на подстилающей поверхности», приведенной на сайте Лаборатории гидрохимии и химии атмосферы Лимнологического института [41] показано, как выполняют отбор проб. Можно предположить, что применяют специальную прямоугольную рамку. А.В. Украинцев также указывает на то, что «снег отбирался на всю его мощность за исключением непосредственного соприкасающегося с почвой слоем. Участок для сбора снега выделялся... рамкой в форме квадрата со сторонами 0,5 м» [42. С. 140].

Отбор снежного покрова с использованием шурфа и послойный отбор проб подробно описан исследователями J.C. Gallet, M.P. Bjorkman, C. Larose и др. Они представили доклад «Protocols and recommendations for the measurement of snow physical properties, and sampling of snow for black carbon, water isotopes, major ions and microorganisms» («Протоколы и рекомендации по измерению физических свойств снега и отбору проб снега на содержание черного углерода, изотопов воды, основных ионов и микроорганизмов») [43].

Отбор проб снежного покрова шпателем. Исследователи $[44,45]$, проводящие отбор проб в полевых условиях, позаботились о том, чтобы предотвратить загрязнение проб. Для этого использовался шпатель из нержавеющей стали, а образцы помещались в пластиковые пакеты, в свою очередь упакованные в пакеты Whirlpack. Пенополистирольные кулеры использовались для транспортировки в лабораторию [44, 45]

Как показывает краткий обзор научно-технической информации [3-6, 31-56], некоторые методики отбора проб для химического анализа являются авторскими, не стандартизированными, что определяется целями анализа, состоянием снежного покрова и географическим местом. Можно отметить, что применяемые методики основаны на классических рекомендациях [7, 10-16].

Также можно отметить, что вид (способ) подготовки снежного покрова выбирается в зависимости от его физических характеристик, места и времени отбора проб, подстилающей поверхности (лед, грунт, склон), целей анализа. Возможно, что исследователи 
делают срез снежного покрова, шурф для отбора слоев или для отбора керна пробы снега в виде столбика цилиндра или прямоугольного параллелепипеда, в основании которого прямоугольник.

Также можно перечислить некоторые этапы выполнения отбора проб непосредственно на месте. Эти этапы не указаны в методических рекомендациях 19701990-х гг. [7, 10-16], но которые из них используют современные исследователи. При выполнении современного отбора проб также целесообразно:

- выполнить регистрацию GPS-координат (включая высоту местности);

- применять специальную одежду, перчатки, маски (хранится в запечатанном виде до отбора проб) при выполнении анализа на микрокомпоненты;

- применить пробоотборник и дополнительные средства из инертного материала, а также пластиковые мешки, полипропиленовые емкости для хранения и транспортировки проб;

- сделать панорамный снимок места отбора пробы. Обзор научно-технической информации, приведенной в данной работе, показывает необходимость обсуждения практики отбора проб с целью повышения достоверности.

Так, в декабре 2017 г. состоялся первый научноисследовательский полевой семинар в ИРНИТУ (г. Иркутск) «Теоретические и практические аспекты исследования снежного покрова: Южный Байкал», на котором была сделана попытка рассмотрения некоторых вопросов отбора проб для химического анализа

\section{СПИСОК ЛИТЕРАТУРЫ}

1. Sturm M., Goldstein M, Parr C. Water and life from snow: a trillion dollar science question // Water Resources Research. 2017. - V. 53. - Iss. 5. - P. 3534-3544.

2. Burakowski E., Magnusson M. Climate impacts on the winter tourism economy in the United States. - New York, NY, USA: Natural Resources Defense Council, 2012. - 36 p. URL file:///C:/Users/ASUS/Downloads/NRDC_POW climate-impactswinter-tourism-reportcopy.pdf (дата обращения: 03.12.2019).

3. Gastineau G., Garcia-Serrano J., Frankignoul C. The influence of autumnal Eurasian snow cover on climate and its link with Arctic Sea ice cover // Journal Climate. - 2017. - V. 30. - P. 7599-7619.

4. Changing Arctic snow cover: a review of recent developments and assessment of future needs for observations, modelling, and impacts / S. Bokhorst, S.H. Pedersen, L. Brucker, O. Anisimov, J.W. Bjerke, R.D. Brown, D. Ehrich, R.L. Essery, A. Heilig, S. Ingvander, C. Johansson, M. Johansson, I.S. Jónsdóttirb, I.N. Niila, K. Luojus, M. Heather, D.D. McLennan, G.N. Rosqvist, A. Sato, N. Savela, M. Schneebeli, S.A. Sokratov, S. Terzago, D. Vikhamar-Schuler, S. Williamson, Y. Qiu, T.V. Callaghan // Ambio. - 2016. - V. 45. - P. 516-537.

5. Witze A. Snow sensors seek best way to track the white stuff // Nature. - 2016. - V. 532. - P. 17.

6. Assessment of future climate change impacts on nonpoint source pollution in snowmelt period for a cold area using SWAT / YuWang, Jianmin Bian, Yongsheng Zhao, Jie Tang, Zhuo Jia. URL: http://www.nature.com/scientificreports (дата обращения: 26.05.2019).

7. Василенко В.Н., Назаров И.М., Фридман Ш.Д. Мониторинг загрязнения снежного покрова. - Л.: Гидрометеоиздат, 1985. $181 \mathrm{c}$.

8. Ветров В.А., Кузовкин В.В., Манзон Д.А. Государственная сеть наблюдений за химическим составом снежного покрова в РФ: итоги и проблемы // Снежный покров, атмосферные осадки, аэрозоли: климат и экология северных территорий и Байкальского региона: Материалы Первой Междунар. научно-
[56]. В программе международных конференций [56] предусмотрена тематика по методологии исследования снежного покрова.

\section{Заключение}

1. Современная практика отбора проб снежного покрова для химического анализа имеет свои особенности, отличные от практик, разработанных в основном в 1990-х гг. Это обусловлено растущим количеством определяемых химических компонентов снежного покрова и требованиями повышения достоверности отбора проб.

2. Современные авторские исследовательские практики отбора проб снежного покрова для химического состава снежного покрова имеют общие этапы и отличия в зависимости от географической точки отбора и определяемого химического компонента.

3. В настоящее время для отбора проб для исследования химического состава снежного покрова применяется большое разнообразие вспомогательных средств, устройств, приспособлений, не входящих в реестр измерительных средств для химического анализа снежного покрова, что вызывает необходимость развития прикладного приборостроения в области химического снеговедения.

4. Для гармонизации измерений целесообразно разработать согласованные методики отбора проб снежного покрова для химического анализа.

практ. конференции. - Иркутск: Изд-во ИРНИТУ, 2017. С. $93-97$.

9. Копанев И.Д. Методы изучения снежного покрова. - Л.: Гидрометеоиздат, 1971. - $226 \mathrm{c}$.

10. Методические рекомендации по геохимической оценке источников загрязнения окружающей среды. - М.: ИМГРЭ, 1982. $-66 \mathrm{c}$.

11. Методические рекомендации по геохимической оценке загрязнения территории городов химическими элементами / Б.А. Ревич, Ю.И. Сает, Р.С. Смирнова, Е.П. Сорокина. - М.: ИМГРЭ, 1982. - $111 \mathrm{c}$.

12. Временные методические указания для производства отбора и обработки проб снегового покрова в городах и их окрестностях на комплекс загрязняющих веществ. - М.: Госкомгидромет СССР, 1985. - $16 \mathrm{c}$

13. РД 52.04.186-89. Руководство по контролю загрязнения атмосферы. http://ipk.meteorf.ru/images/stories/literatura/rd/52.04.186_89.pdf (дата обращения 03.12.2019).

14. Методические рекомендации по оценке степени загрязнения атмосферного воздуха населенных пунктов металлами по их содержанию в снежном покрове и почве. - М.: ИМГРЭ, 1990. - 16 c. URL: http://www.alppp.ru/law/zdravoohranenie-fizicheskaja-kultura-i-sport--turizm/zdravoohranenie/59/ metodicheskie-rekomendacii-po-ocenke-stepeni-zagrjaznenijaatmosfernogo-vozduha-naselennyh.pdf (дата обращения 03.12.2019).

15. Геохимия окружающей среды / Ю.Е. Сает, Б.А. Ревич, Е.П. Янин, Р.С. Смирнова, И.Л. Барашкевич, Т.Л. Онищенко, Л.Н. Павлова, Н.Я. Трефилова, А.И. Ачкасов, С.Ш. Саркисян. - М.: Изд-во «Недра», 1990. - 335 с.

16. РД 52.44.2-94 Руководящий документ. Методические указания. Охрана природы. Комплексное обследование загрязнения природных сред промышленных районов с интенсивной антропогенной нагрузкой. URL: http://ipk.meteorf.ru/images/ stories/literatura/rd/52.44.2_94.pdf (дата обращения 03.12.2019).

17. Методические рекомендации. Оценка аэротехногенного загрязнения природных сред химическими элементами по ре- 
зультатам мониторинга снежного покрова. Утв. приказом Министра экологии и природных ресурсов Республики Татар стан от 26.02.2010 г. № 131. - Казань, 2010. - 16 с. URL: https://studylib.ru/doc/3892257/4.5.-opredelenie-postuplenijhimicheskih-e-lementov (дата обращения: 10.11.2019).

18. Р 52.18.851-2016 О введении в действие рекомендаций. Основные средства измерений гидрометеорологического назначения, применяемые на государственной наблюдательной сети. Обнинск: ФГБУ «ВНИИГМИ-МЦД», 2016. - 80 с.

19. Снегомер ВC-43. Руководство по эксплуатации. URL: http:// pp66.ru/uploadedFiles/images/gydrometeo/Snegomer_VS-43 rukovodstvo_po_ekspluatatsii.pdf (дата обращения: 10.11.2019).

20. Козин В.В., Козин В.В., Кузнецова Э.А. Физикогеографические факторы пространственно-временной изменчивости снежного покрова нефтегазопромыслового региона. Нижневартовск: Нижневартовский государственный университет, 2015. - $151 \mathrm{c}$.

21. ВС-43М Снегомер весовой № 57925-14, сертификат № 56178 . URL: https://fgis.gost.ru/fundmetrology/registry/4/items/370865 (дата обращения: 03.12.2019).

22. Способ отбора проб снега и устройство для его осуществления: пат. Рос. Федерация. № 2047121, G01N1/20; заявл. 14.01.1993; опубл. 27.10.1995. http://www.findpatent.ru/patent/ 204/2047121.html (дата обращения: 15.11.2020)

23. Устройство для отбора проб снега: пат. Рос. Федерация RU2247351C2. URL: https://findpatent.ru/patent/224/2247351.htm (дата обращения 01.09.2019).

24. Пробоотборник снегомерный: пат. Рос. Федерация, № RU 80587 U1; заявл. 29.07.2008. опубл. 10.02.2009

25. Руководство по отбору образцов снежного покрова. Процеду ры отбора проб. URL: https://www.wcc.nrcs.usda.gov/factpub/ ah169/ah169p05.htm (дата обращения: 17.04.2019).

26. Dixon D., Boon S. Comparison of the SnowHydro snow sampler with existing snowtube designs in southwestern Alberta, Canada // Proceedings of LXVIII eastern snow conference. - Montreal, Quebec: McGill University, 2011. - P. 207-224.

27. Kinar N.J., Pomeroy J.W. Measurement of the physical properties of the snowpack // Reviews of Geophysics. - 2015. - V. 53. Iss. 2. - P. 481-544.

28. Church J.E. Snow surveying: its principles and possibilities // Geographical Review. - 1933. - V. 23. - P. 529-563.

29. Metrication of manual snow sampling equipment by western snow conference metrication committee / P.E. Farnes, N.R. Peterson, B.E. Goodison, R.P. Richards // Proceedings of the 50th Annual Western Snow Conference. - Reno, Nevada, 1982. - P. 120-132. URL: https://westernsnowconference.org/node/918 (дата обращения 11.12.2019)

30. European in-situ snow measurements: practices and purposes / R. Pirazzini, L. Leppänen, G. Picard, J.I. Lopez-Moreno, C. Marty, G. Macelloni, A. Kontu, A. Lerber, C.M. Tanis, M. Schneebeli, P. Rosnay, A.N. Arslan // Sensors (Basel). - 2018. - V. 18 (7). URL: https://doi.org/10.3390/s18072016 (дата обрашения 11.12.2019).

31. Тентюков М.П. Особенности послойной изменчивости интегральных физико-химических параметров снежного покрова в среднетаежной зоне на северо-востоке европейской равнины // Криосфера Земли. - 2018. - Т. XXII. - № 2. - С. 61-69.

32. Маслобоев В.А., Горбачева Т.Т., Евдокимова Г.А., Казаков Л.А., Переверзев В.Н., Похилько А.А., Раткин Н.Е. Экологическое состояние наземных и водных экосистем в районе Кольской АЭС. - Апатиты: Изд-во Кольский научный центр PAH, 2010. - $227 \mathrm{c}$

33. Геохимия снежного покрова в восточном округе Москвы Н.С. Касимов, Н.Е. Кошелева, Д.В. Власов, Е.В. Терская // Вестник Московского университета. Серия 5: География. 2012. - № 4. - С. 14-24.

34. Аэротехногенный мониторинг состояния городской среды по загрязнению снежного покрова (на примере города Воронеж) / Т.И. Прожорина, Е.В. Беспалова, С.А. Куролап, П.М. Виноградов // Вестник Волгоградского государственного университета. Серия 11: Естественные науки. - 2014. - № 3. С. 28-34.

35. Химический состав снега на урбанизированных территориях в условиях Крайнего Севера / Н.В. Салтан, Е.П. Шлапак, В.К. Жиров, О.Б. Гонтарь, Е.А. Святковская // Вестник МГТУ. - 2015. - Т. 18. - № 2. - С. 328-334
36. Снегоотборник: пат. Рос. Федерация. RU 53436 U1; Номер заявки: 2005123013/22 заявл: 19.07.2005; опубл: 10.05.2006.

37. Влияние поверхностного загрязнения на ледники Кавказа. URL: http://paleoglaciology.org/ru/regions/Caucasus/DIOGENES/ (дата обращения: 28.08.2019).

38. Петрига А.А., Горюнова Н.В. Состав снега в импактных районах Арктики на примере поселков залива Ис-фьорд архипелага Шпицберген // Вестник науки и образования. - 2016. № 2. - C. 106-110.

39. Макаров В.Н., Федосеев Н.Ф., Федосеева В.И. Геохимия снежного покрова Якутии. - Якутск: Институт мерзлотоведения СО РАН СССР, 1990. - 152 с

40. Химический состав снежного покрова в заповедниках Прибайкалья / О.Г. Нецветаева, Т.В. Ходжер, Л.П. Голобокова, Н.А. Кобелева, Т.В. Погодаева // География и природные ресурсы. - 2004. - № 1. - С. 66-72.

41. Лаборатория гидрохимии и химии атмосферы. URL: http://www. lin.irk.ru/hydrochem/workdays (дата обращения 01.09.2019).

42. Украинцев А.В. Нерастворимые дисперсные частицы в снежном покрове в районах лесных пожарищ // Снежный покров, атмосферные осадки, аэрозоли: климат и экология северных территорий и Байкальского региона: Материалы Первой Международной научно-практической конференции. - Иркутск: Иркутский национальный исследовательский технический университет, 2017. - С. 139-142.

43. Protocols and recommendations for the measurement of snow physical properties, and sampling of snow for black carbon, water isotopes, major ions and microorganisms / J.-Ch. Gallet, M.P. Björkman, C. Larose, B. Luks, T. Martma, C. Zdanowicz. URL: https://brage.npolar.no/npolar-xmlui/browse?type=author\& value $=$ Gallet\%2C+Jean-Charles (дата обращения 14.12.2019).

44. Elemental and mineralogical composition of the Western Andean snow $\left(18^{\circ} \mathrm{S}-41^{\circ} \mathrm{S}\right) /$ J.A. Alfonso, R.R. Cordero, P.M. Rowe, P.M. Rowe, S. Neshyba, G. Casassa, J. Carrasco, S. MacDonell, F. Lambert, J. Jaime Pizarro, F. Fernandoy, S. Feron, A. Damiani, P. Llanillo, E. Sepulveda, J. Jorquera, B. Garcia, J.M. Carrera, P. Oyola, C-M. Kang // Scientific Reports. - 2019. - V. 9. DOI: 10.1038/s41598-019-39312-0 URL: https://www.nature.com/ articles/s41598-019-44516-5 (дата обращения 03.12.2019).

45. Black carbon and other light-absorbing impurities in snow in the Chilean Andes / P.M. Rowe, R.R. Cordero, S.G. Warren, E. Stewart, S.J. Doherty, A. Pankow, M. Schrempf, G. Casassa, J. Carrasco, J. Pizarro, S. MacDonell, A. Damiani, F. Lambert, R. Rondanelli, N. Huneeus, F. Fernandoy, S. Neshyba // Scientific Reports. - 2019. - V. 9. - Article number 40084008.

46. Hair geochemical composition of children from Vilnius kindergartens as an indicator of environmental conditions / R. Taraskevicius, R. Zinkute, L. Gedminiene, Z. Stankevicius // Environ Geochem Health. - 2018. - V. 40. - Iss. 5. - P. 1817-1840.

47. Polycyclic aromatic hydrocarbons in fresh snow in the city of Harbin in northeast China / Song Cui, Zihan Song, Leiming Zhang, Zulin Zhang, Rupert Hough, Qiang Fu, Lihui An, Zhenxing Shen, Yi-Fan Li, Dong Liu, Shang Gao // Atmospheric Environment. 2019. - V. 215. DOI: 10.1016/j.atmosenv.2019.116915

48. Signals of pollution revealed by trace elements in recent snow from mountain glaciers at the Qinghaie-Tibetan plateau / Yuefang Li, Zhen Li, G. Cozzi, C. Turetta, C. Barbante, Ju Huang, Longfei Xiong // Chemosphere. - 2018. - V. 200. - P. 523-531.

49. Gustaytis M.A., Myagkaya I.N., Chumbaev A.S. Hg in snow cover and snowmelt waters in high-sulfide tailing regions (Ursk tailing dump site, Kemerovo region, Russia) // Chemosphere. - 2018. V. 202. - P. 446-459.

50. Characterization of solid airborne particles deposited in snow in the vicinity of urban fossil fuel thermal power plant (Western Siberia) / A.V. Talovskaya, E.G. Yazikov, E.A. Filimonenko, J.-C. Lata, J. Kim, T.S. Shakhova // Environmental Technology. 2018. - V. 39. - Iss. 18. - P. 2288-2303.

51. Converting snow depth to snow water equivalent using climatological variables / D.F. Hill, E.A. Burakowski, R.L., Crumley J. Keon, J.M. Hu, A.A. Arendt, J.K. Wikstrom, G.J. Wolken // The Cryosphere. - 2019. - V. 13. - P. 1767-1784.

52. Chemistry of snow cover and acidic snowfall during a season with a high level of air pollution on the Hans Glacier / A.P. Nawrot, K. Migała, B. Luks, P., Pakszys P. Głowacki // Spitsbergen Polar Science. - 2016. - V. 10. - Iss. 3. - P. 249-261. 
53. Seasonal variations in the major chemical species of snow at the South East Dome in Greenland / I. Oyabu, S. Matoba, T. Yamasaki, M. Kadota, Y. Iizuka // Polar Science. - 2016. V. 10. - Iss. 1. - P. 36-42

54. Dynamics of ionic species in Svalbard annual snow: the effects of rain event and melting / E. Barbaro, C. Varin, X. Pedeli, J.M. Christille, T. Kirchgeorg, F. Giardi, D. Cappelletti, C. Turetta, A. Gambaro, A. Bernagozzi, J.C. Gallet, M.P. Björkman, A. Spolaor // The Cryosphere Discuss. 2019. URL: https://www.the-cryosphere-discuss.net/tc-2019-124/ (дата обращения 17.12.2019).

55. Specifying the light-absorbing properties of aerosol particles in fresh snow samples, collected at the Environmental Research Station Schneefernerhaus (UFS), Zugspitze / M. Schnaiter,
C. Linke, I. Ibrahim, A. Kiselev, F. Waitz, T. Leisner, S. Norra, T. Rehm // Atmospheric Chemistry and Physics. - 2019. - V. 19. P. $10829-10844$

56. Янченко Н.И., Букин Ю.С., Баранов А.Н. Первый научноисследовательский полевой семинар «Теоретические и практические аспекты исследования снежного покрова: Южный Байкал» // Снежный покров, атмосферные осадки, аэрозоли: технология, климат и экология: Материалы Второй Байкальской Междунар. научно-практ. конф. - Иркутск: Иркутский национальный исследовательский технический университет, 2018. - C. $247-253$.

Поступила 18.11.2020 г.

\section{Информация об авторах}

Янченко Н.И., доктор технических наук, профессор Института высоких технологий Иркутского национального исследовательского технического университета. 


\title{
PRACTICE OF SNOW COVER SAMPLING FOR CHEMICAL ANALYSIS
}

\author{
Natalia I. lanchenko, \\ fduecn@bk.ru \\ Irkutsk National Research Technical University, \\ 83, Lermontov street, Irkutsk, 664074, Russia.
}

The relevance of the research is caused by the need to study snow cover chemical composition to assess air quality and adjacent environments under climate change, which is confirmed by the steady growth of scientific publications on this topic. At the same time, there are practically no modern publications on the methodology for sampling snow cover for analytical purposes.

The main aim: to study snow cover sampling practices for analytical definitions based on a review of scientific and technical information. Modern improved snow sampling techniques are needed to obtain the most reliable data on chemical composition of snow cover, provide a basis for assessing air quality dynamics and environmental protection outcomes, and will contribute to the scientific understanding of the chemical processes associated with snow under climate change.

Objects: information on regulatory and scientific and technical literature in the Russian Federation on the methodology for sampling snow cover for chemical analysis; methods for preparing snow cover before sampling; instruments, equipment, means, devices for sampling snow cover in order to determine the density (physical indicator) and chemical composition of the snow cover.

Methods: review of scientific and technical information and data systematization.

Result. The current practice of sampling snow cover for chemical analysis has its own characteristics that differ from practices developed mainly in the 1990s. This is due to the growing number of determined chemical components of the snow cover and the requirements for the reliability of sampling. Modern, original practices of snow cover sampling for the chemical composition of the snow cover have common stages and differences depending on the geographical point of sampling and the determined chemical component. At present, a wide variety of auxiliary tools and devices not included in the register of measuring instruments for the chemical analysis of snow cover are used for sampling to study the chemical composition of snow cover, which necessitates the development of applied instrumentation in the field of chemical snow science. It is advisable to develop harmonized snow cover sampling techniques for chemical analysis.

\section{Key words:}

Snow cover, sampling, sampler, chemical component, method.

\section{REFERENCES}

1. Sturm M., Goldstein M., Parr C. Water and life from snow: a trillion dollar science question. Water Resources Research, 2017, vol. 53, Iss. 5, pp. 3534-3544.

2. Burakowski E., Magnusson M. Climate impacts on the winter tourism economy in the United States. New York, NY, USA, Natural Resources Defense Council, 2012. 36 p. Available at: https://protectourwinters.org/climate_report/report.pdf (accessed 2 December 2019).

3. Gastineau G., Garcia-Serrano J., Frankignoul C. The influence of autumnal Eurasian snow cover on climate and its link with Arctic Sea ice cover. Journal Climate, 2017, vol. 30, pp. 7599-7619.

4. Bokhorst S., Pedersen S.H., Brucker L., Anisimov O., Bjerke J.W., Brown R.D., Ehrich D., Essery R.L., Heilig A., Ingvander S., Johansson C., Johansson M., Jónsdóttirb I.S., Niila I.N., Luojus K., Heather M., McLennan D.D., Rosqvist G.N., Sato A., Savela N., Schneebeli M., Sokratov S.A., Terzago S., Vikhamar-Schuler D., Williamson S., Qiu Y., Callaghan T.V. Changing Arctic snow cover: a review of recent developments and assessment of future needs for observations, modelling, and impacts. Ambio, 2016, vol. 45 , pp. 516-537.

5. Witze A. Snow sensors seek best way to track the white stuff. $\mathrm{Na}$ ture, 2016, vol. 532, p. 17.

6. Yu Wang, Jianmin Bian, Yongsheng Zhao, Jie Tang, Zhuo Jia. As sessment of future climate change impacts on nonpoint source pollution in snowmelt period for a cold area using SWAT 10.1038/s41598-018-20818-y. Available at: http://www.nature. com/scientificreports (accessed 26 May 2019).

7. Vasilenko V.N., Nazarov I.M., Fridman Sh.D. Monitoring zagryazneniya snezhnogo pokrova [Monitoring of snow cover pollution]. Leningrad, Gidrometeoizdat Publ., 1985. 181 p.

8. Vetrov V.A., Kuzovkin V.V., Manzon D.A. Gosudarstvennaya set nablyudeniy za khimicheskim sostavom snezhnogo pokrova v RF: itogi i problemy [State network of observations of the chemical composition of snow cover in the Russian Federation: results and problems]. Snezh ny pokrov, atmosfernye osadki, aerozoli: klimat i ekologiya severnykh territoriy i Baykalskogo regiona. Materialy I mezhdunarodnoy nauch no-prakticheskoy konferentsii [Snow cover, precipitation, aerosols: climate and ecology of the Northern territories and the Baikal region: proceedings of the I International scientific and practical conference]. Irkutsk, INRTU Publ., 2017. pp. 93-97.

9. Kopanev I.D. Metody izucheniya snezhnogo pokrova [Methods of studying the snow cover]. Leningrad, Gidrometeoizdat Publ., 1971 $226 \mathrm{p}$.

10. Metodicheskie rekomendatsii po geokhimicheskoy otsenke istochnikov zagryazneniya okruzhayushchey sredy [Methodological recommendations for geochemical assessment of environmental pollution sources]. Moscow, IMGRE Publ., 1982. 66 p.

11. Revich B.A., Saet Yu.I., Smirnova R.S., Sorokina E.P. Metodicheskie rekomendatsii po geokhimicheskoy otsenke zagryazneniya territorii gorodov khimicheskimi elementami [Guidelines for geochemical assessment of urban pollution by chemical elements]. Moscow, IMGRE Publ., 1982. $111 \mathrm{p}$.

12. Vremennye metodicheskie ukazaniya dlya proizvodstva otbora $i$ obrabotki prob snegovogo pokrova v gorodakh i ikh okrestnostyakh na kompleks zagryaznyayushchikh veshchestv [Temporary guidelines for the production selection and processing of samples of snow cover in cities and their surroundings on the complex of pollutants]. Moscow, Goskomgidromet Publ., 1985. 16 p. Available at: http://ipk.meteorf.ru/images/stories/literatura/rd/ 52.04.186_89.pdf (accessed 3 December 2019).

13. $R D$ 52.04.186-89 Rukovodstvo po kontrolyu zagryazneniya atmosfery [Manual on air pollution control]. Part 2, p. 5.1.2. Moscow, Goskomgidromet Publ., 1991. 65 p.

14. Metodicheskie rekomendatsii po otsenke stepeni zagryazneniya atmosfernogo vozdukha naselennykh punktov metallami po ikh soderzhaniyu $v$ snezhnom pokrove i pochve [Methodological recommendations for assessing the degree of air pollution of settlements metals on their content in the snow cover and soil]. Moscow, IMGRE Publ., 1990. 5 p. Available at: http://www.alppp.ru/ law/zdravoohranenie--fizicheskaja-kultura-i-sport--turizm/zdravoohranenie/59/metodicheskie-rekomendacii-po-ocenke-stepenizagrjaznenija-atmosfernogo-vozduha-naselennyh.pdf (accessed 3 December 2019).

15. Saet Yu.E., Revich B.A., Yanin E.P., Smirnova R.S., Barashkevich I.L., Onishchenko T.L., Pavlova L.N., Trefilova N.Ya., 
Achkasov A.I., Sarkisyan S.Sh. Geokhimiya okruzhayushchey sredy [Geochemistry of the environment]. Moscow, Nedra Publ., 1990. $335 \mathrm{p}$.

16. RD 52.44.2-94 Rukovodyashchiy dokument. Metodicheskie ukazaniya. Okhrana prirody. Kompleksnoe obsledovanie zagryazneniya prirodnykh sred promyshlennykh rayonov s intensivnoy antropogennoy nagruzkoy [Guidance document. Methodical instructions. Nature protection. Comprehensive survey of pollution of natural environments of industrial areas with intensive anthropogenic load]. Moscow, IGKE Publ., 1988. Available at: http://ipk. meteorf.ru/images/stories/literatura/rd/52.44.2_94.pdf (accessed 3 December 2019).

17. Metodicheskie rekomendatsii. Otsenka aerotekhnogennogo zagryazneniya prirodnykh sred khimicheskimi elementami po rezultatam monitoringa snezhnogo pokrova [Methodical recommendation. Assessment of aerotechnogenic pollution of natural environments by chemical elements based on the results of snow cover monitoring]. Available at: https://studylib.ru/doc/3892257/4.5.-opredeleniepostuplenij-himicheskih-e-lementov (accessed 10 November 2019).

18. $R$ 52.18.851-2016 O vvedenii v deystvie rekomendatsy. Osnovnye sredstva izmereniy gidrometeorologicheskogo naznacheniya, primenyaemye na gosudarstvennoy nablyudatelnoy seti [On implementation of the recommendations. Main hydrometeorological measuring instruments used on the state observation network]. Moscow, Rosgidromet, 2016. $80 \mathrm{p}$.

19. Snegomer VS-43. Instruktsiya po ekspluatatsii [Snow gauge VS-43 Operation manual]. http://pp66.ru/uploadedFiles/images/ gydrometeo/Snegomer_VS-43_rukovodstvo_po_ekspluatatsii.pdf (accessed 11 December 2019).

20. Kozin V.V., Kozin V.V., Kuznetsova E.A. Fiziko-geograficheskie faktory prostranstvenno-vremennoy izmenchivosti snezhnogo pokrova neftegazopromyslovogo regiona [Physical and geographical factors of spatial and temporal variability of snow cover of oil and gas field region]. Nizhnevartovsk, Nizhnevartovsk State University Publ., 2015. $151 \mathrm{p}$

21. VS-43M Snegomer vesovoy [Snow meter weight]. Available at: https://fgis.gost.ru/fundmetrology/registry/4/items/370865 (accessed 3 December 2019).

22. Gulyakin G.G. Sposob otbora prob snega i ustroystvo dlya ego osushchestvleniya [Method of sampling snow and device for its implementation]. Patent RF, no. 2047121, 1995.

23. RU2247351C2 Ustroystvo dlya otbora prob snega [A device for snow sampling]. Available at: https://findpatent.ru/patent/ 224/2247351.html (accessed 1 September 2019).

24. Sergeev A.P., Buevich A.G., Berg D.B. Probootbornik snegomerny [Snow measuring sampler]. Patent RF, no. RU 80587 U1, 2009.

25. Rukovodstvo po otboru obraztsov snezhnogo pokrova. Protsedury otbora prob [Manual sampling of the snow cover. Sampling procedure]. Available at: https://www.wcc.nrcs.usda.gov/factpub/ ah169/ah169p05.htm (accessed 17 April 2019).

26. Dixon D., Boon S. Comparison of the SnowHydro snow sampler with existing snowtube designs in southwestern Alberta, Canada. Proceedings of LXVIII eastern snow conference. Montreal, Quebec, McGill University Publ., 2011. pp. 207-224.

27. Kinar N.J., Pomeroy J.W. Measurement of the physical properties of the snowpack. Reviews of Geophysics, 2015, vol. 53, Iss. 2, pp. 481-544.

28. Church J.E. Snow surveying: its principles and possibilities. Geographical Review, 1933, vol. 23, pp. 529-563.

29. Farnes P.E., Peterson N.R., Goodison B.E., Richards R.P. Metrication of manual snow sampling equipment by western snow conference metrication committee. Proceedings of the $50^{\text {th }}$ Annual Western Snow Conference. Reno, Nevada, 1982. pp. 120-132. Available at: https://westernsnowconference.org/node/918 (accessed 11 December 2019).

30. Pirazzini R., Leppänen L., Picard G., Lopez-Moreno J.I., Marty C., Macelloni G., Kontu A., Lerber A., Tanis C.M., Schneebeli M., Rosnay P., Arslan A.N. European in-situ snow measurements: practices and purposes. Sensors, 2018, vol. 18. Avaialble at: https://doi.org/10.3390/s18072016 (accessed 11 December 2019).

31. Tentyukov M.P. Features of layer-by-layer variability of integrated physical and chemical parameters of snow cover in the middle taiga zone in the North-East of the European plain. Kriosfera Zemli, 2018, vol. XXII, no. 2, pp. 61-69. In Rus.
32. Masloboev V.A., Gorbacheva T.T., Evdokimova G.A Ekologicheskoe sostoyanie nazemnykh $i$ vodnykh ekosistem v rayone Kolskoy AES [Ecological state of terrestrial and aquatic ecosystems in the Kola NPP area]. Apatity, Kola science centre RAN Publ., 2010. 227 p.

33. Kasimov N.S., Kosheleva N.E., Vlasov D.V., Terskaya E.V. Snow cover geochemistry in eastern region of Moscow. Bulletin of Moscow University. Series 5: Geography, 2012, no. 4, pp. 14-24. In Rus.

34. Prozhorina T.I., Bespalova E.V., Kurolap S.A., Vinogradov P.M. Aerotekhnogenny monitoring sostoyaniya gorodskoy sredy po zagryazneniyu snezhnogo pokrova (na primere goroda Voronezh) [Aerotechnogenic monitoring of city environment state by snow cover contamination (on the example of Voronezh)]. Bulletin of Volgograd state University. Series 11: Natural Sciences, 2014, no. 3, pp. 28-34.

35. Saltan N.V., Shlapak E.P., Zhirov V.K., Gontar O.B., Svyatkovskaya E.A. Snow chemical composition in urban territories in the Arctic. Bulletin of the Moscow State technical University, 2015, vol. 18, no. 2, pp. 328-334. In Rus.

36. Valetdinov A.R., Valetdinov R.K., Gorshkova A.T. Snegootbornik [Snow collector]. Patent RF, no. 53436, 2006.

37. Vliyanie poverkhnostnogo zagryazneniya na ledniki Kavkaza [Influence of surface pollution on the glaciers of the Caucasus]. Available at: http://paleoglaciology.org/ru/regions/Caucasus/ DIOGENES/ (accessed 28 August 2019).

38. Petriga A.A., Goryunova N.V. Snow composition in the impact regions of the Arctic on the example of the Is-fjord Bay settlements of the Svalbard archipelago. Bulletin of Science and education, 2016, no. 2, pp. 106 -110. In Rus.

39. Makarov V.N., Fedoseev N.F., Fedoseeva V.I. Geokhimiya snezhnogo pokrova Yakutii [Geochemistry of the snow cover of Yakutia]. Yakutsk, Institute of permafrost SB RAS USSR Publ., 1990. $152 \mathrm{p}$.

40. Netsvetaeva O.G., Khodzher T.V., Golobokova L.P., Kobeleva N.A., Pogodaeva T.V. Khimicheskiy sostav snezhnogo pokrova v zapovednikakh Pribaykalya [Snow cover chemical composition in Baikal region reservations]. Geography and natural resources, 2004, no. 1, pp. 66-72.

41. Laboratoriya gidrokhimii i khimii atmosfery [Laboratory of hydrochemistry and atmospheric chemistry]. Available at: http://www. lin.irk.ru/hydrochem/workdays (accessed 1 September 2019).

42. Ukraintsev A.V. Nerastvorimye dispersnye chastitsy v snezhnom pokrove $\mathrm{v}$ rayonakh lesnykh pozharishch [Insoluble dispersed particles in snow cover in forest fires]. Snezhny pokrov, atmosfernye osadki, aerozoli: klimat $i$ ekologiya severnykh territoriy $i$ Baykalskogo regiona. Materialy I mezhdunarodnoy nauchnoprakticheskoy konferentsii [Snow cover, precipitation, aerosols: climate and ecology of the Northern territories and the Baikal region: proceedings of the I international scientific and practical conference]. Irkutsk, Irkutsk national research technical University Publ., 2017. pp. 139-142.

43. Gallet J.-Ch., Björkman M.P., Larose C., Luks B., Martma T., Zdanowicz C. Protocols and recommendations for the measurement of snow physical properties, and sampling of snow for black carbon, water isotopes, major ions and microorganisms. Available at: https://brage.npolar.no/npolar-xmlui/browse?type=author\& value $=$ Gallet\%2C+Jean-Charles (accessed 1 September 2019).

44. Alfonso J.A., Cordero R.R., Rowe P.M., Rowe P.M., Neshyba S., Casassa G., Carrasco J., MacDonell S., Lambert F., Jaime Pizarro J., Fernandoy F., Feron S., Damiani A., Llanillo P., Sepulveda E., Jorquera J., Garcia B., Carrera J.M., Oyola P., Kang C-M. Elemental and Mineralogical Composition of the Western Andean Snow $\left(18^{\circ} \mathrm{S}-41^{\circ} \mathrm{S}\right)$. Scientific Reports, 2019, vol. 9. DOI: 10.1038/s41598-019-39312-0 Available at: https://www.nature. com/articles/s41598-019-44516-5 (accessed 11 December 2019).

45. Rowe P.M., Cordero R.R., Warren S.G. Black carbon and other light-absorbing impurities in snow in the Chilean Andes. Scientific Reports, 2019, vol. 9, Article number 40084008.

46. Taraskevicius R., Zinkute R., Gedminiene L., Stankevicius Z. Hair geochemical composition of children from Vilnius kindergartens as an indicator of environmental conditions. Environ Geochem Health, 2018, vol. 40, Iss. 5, pp. 1817-1840.

47. Song Cui, Zihan Song, Leiming Zhang, Zulin Zhang, Rupert Hough, Qiang Fu, Lihui An, Zhenxing Shene, Yi-Fan Lif, Dong 
Liu, Shang Gao. Polycyclic aromatic hydrocarbons in fresh snow in the city of Harbin in northeast China. Atmospheric Environment, 2019, vol. 215. DOI: 10.1016/j.atmosenv.2019.116915

48. Yuefang Li, Zhen Li, Cozzi G., Turetta C., Barbante C., Ju Huang, Longfei Xiong. Signals of pollution revealed by trace elements in recent snow from mountain glaciers at the Qinghaie Tibetan plateau. Chemosphere, 2018. vol. 200, pp. 523-531.

49. Gustaytis M.A., Myagkaya I.N., Chumbaev A.S. Hg in snow cover and snowmelt waters in high-sulfide tailing regions (Ursk tailing dump site, Kemerovo region, Russia). Chemosphere, 2018, vol. 202, pp. 446-459.

50. Talovskaya A.V., Yazikov E.G., Filimonenko E.A., Lata J.-C., Kim J., Shakhova T.S. Characterization of solid airborne particles deposited in snow in the vicinity of urban fossil fuel thermal power plant (Western Siberia). Environmental Technology, 2018, vol. 39, Iss. 18, pp. 2288-2303.

51. Hill D.F., Burakowski E.A., Crumley R.L., Keon J., Hu J.M., Arendt A.A., Wikstrom J.K., Wolken G.J. Converting snow depth to snow water equivalent using climatological variables. The Cryosphere, 2019, vol. 13, pp. 1767-1784.

52. Nawrot A.P., Migała K., Luks B., Pakszys P., Głowacki P. Chemistry of snow cover and acidic snowfall during a season with a high level of air pollution on the Hans Glacier. Spitsbergen Polar Science, 2016, vol. 10, Iss. 3, pp. 249-261.

53. Oyabu I., Matoba S., Yamasaki T., Kadota M., Iizuka Y. Seasonal variations in the major chemical species of snow at the South East Dome. Greenland Polar Science, 2016, vol. 10, pp. 36-42.
54. Barbaro E., Varin C., Pedeli X., Christille J. M., Kirchgeorg T., Giardi F., Cappelletti D., Turetta C., Gambaro A., Bernagozzi A., Gallet J.C., Björkman M.P., Spolaor A. Dynamics of ionic species in Svalbard annual snow: the effects of rain event and melting. The Cryosphere Discuss, 2019. Available at: https://www.thecryosphere-discuss.net/tc-2019-124/ (accessed 17 December 2019).

55. Schnaiter M., Linke C., Ibrahim I., Kiselev A., Waitz F., Leisner T., Norra S., Rehm T. Specifying the light-absorbing properties of aerosol particles in fresh snow samples, collected at the Environmental Research Station Schneefernerhaus (UFS), Zugspitze. Atmospheric Chemistry and Physics, 2019. vol. 19, pp. 10829-10844.

56. Ianchenko N.I., Bukin Yu.S., Baranov A.N. Pervy nauchnoissledovatelskiy polevoy seminar «Teoreticheskie i prakticheskie aspekty issledovaniya snezhnogo pokrova: Yuzhny Baykal» [The first research field seminar «Theoretical and practical aspects of the study of the snow cover of southern Baikal»]. Snezhny pokrov, atmosfernye osadki, aerozoli: tekhnologiya, klimat i ekologiya. Materialy II Baykalskoy mezhdunarodnoy nauchno-prakticheskoy konferentsii [Snow cover, precipitation, aerosols: technology, climate and ecology: proceedings of the II Baikal international scientific and practical conference]. Irkutsk, Irkutsk national research technical University Publ., 2018. pp. 247-253.

Received: 18 November 2020.

\section{Information about the authors}

Natalia I. Ianchenko, Dr. Sc., professor, Irkutsk National Research Technical University. 